\title{
Stromal and intraepithelial tumor-infiltrating lymphocytes in colorectal carcinoma
}

\author{
KATARZYNA JAKUBOWSKA ${ }^{1}$, WOJCIECH KISIELEWSKI ${ }^{2}$, LUIZA KAŃCZUGA-KODA ${ }^{1}$, \\ MARIUSZ KODA ${ }^{3}$ and WALDEMAR FAMULSKI ${ }^{1,2}$ \\ ${ }^{1}$ Department of Pathomorphology, Comprehensive Cancer Center, 15-027 Bialystok; Departments of \\ ${ }^{2}$ Medical Pathomorphology and ${ }^{3}$ General Pathomorphology, Medical University of Bialystok, 15-269 Bialystok, Poland
}

Received March 27, 2017; Accepted June 15, 2017

DOI: 10.3892/ol.2017.7013

\begin{abstract}
The local mechanisms of antitumor immune defense determine the development and organization of the tumor microenvironment, and the composition and relative proportions of the inflammatory cell population affect the quality and characteristics of the immune response. The aim of the present study was to conduct a quantitative morphological evaluation of two types of tumor-infiltrating lymphocyte (TILs) populations, including those located in the stroma and intraepithelial cancer structures, in the invasive front and the center of the tumor in patients with colorectal cancer (CRC). The study included 160 patients with CRC who had undergone surgery. The tissue material was stained with hematoxylin and eosin, as used in routine histopathological diagnosis, and the two TIL populations were observed and counted with light microscopy. The relative extent of infiltration of stromal and intraepithelial TILs into the front and center of the primary tumors was similar. The extent of infiltration by stromal TILs was negatively correlated with the morphological features of tumor progression including the cancer infiltration of blood vessels $(\mathrm{P}=0.016)$, the invasion of lymph vessels $(\mathrm{P}=0.007)$, perineural invasion $(\mathrm{P}=0.036)$, lymph node involvement $(\mathrm{P}=0.047)$ and distant metastases $(\mathrm{P}=0.032)$. The infiltration by intraepithelial TILs was positively correlated with a desmoplastic reaction $(\mathrm{P}=0.002)$. Disease-free survival time was statistically shorter in patients without intraepithelial TILs in the center of the primary tumor mass $(\mathrm{P}=0.049$; hazard ratio $=1.45)$. These results confirm that the infiltration of TILs into the invasive front and center of the tumor in patients with CRC serves an important role in the invasion and progression of the disease, and should be considered in routine histopathological examinations.
\end{abstract}

Correspondence to: Dr Katarzyna Jakubowska, Department of Pathomorphology, Comprehensive Cancer Center, 12 Ogrodowa Street, 15-027 Bialystok, Poland

E-mail:kathian@wp.pl

Key words: tumor-infiltrating lymphocytes, colorectal cancer, immune response

\section{Introduction}

The development of tumors is a multistep process in which the immune response serves an important role. The local immune antitumor defense mechanisms determine the development and organization of the tumor microenvironment; the composition of the cell population and the relative proportion of inflammatory cells present in this area affect the quality and characteristics of the inflammatory response (1). Lymphocytes isolated directly from the tumor environment are termed tumor-infiltrating lymphocytes (TILs). They recognize tumor antigens and directly induce tumor lysis, or release specific chemotactic and pro-inflammatory cytokines (2). Using electron microscopy, it was observed that at tumor cells in direct contact with TILs, there was evidence of the destruction of cell membranes and cytoplasm, and in certain cases, penetration inside the cancer cell and destruction of the cell nucleus (3).

In modern anticancer treatment, immunotherapy to stimulate or inactivate specific cell populations to activate the immune response against tumor cells is in increasing use (4). The evaluation of the presence and degree of lymphocytic infiltration is performed in the routine histopathological examinations for the diagnosis of malignant melanoma. Lymphocytic infiltration at the edge of the lesion and infiltration between cancer cells are positive prognostic markers for patients with malignant melanoma (5). The risk of regional lymph nodes metastasis and mortality due to malignant melanoma decreases with the increasing degree of lymphocytic infiltration $(6,7)$. Patients with high TIL infiltration may respond to the administration of ipilimumab antibodies against cytotoxic T-lymphocyte associated protein 4 , with the effect of reducing immune inhibition to promote an immune response against the tumor (8). An additional target that appears to exhibit potential for immunotherapy is programmed cell death protein 1 (PD1) protein and its ligand, which is expressed on a high proportion of active TILs of lymphoma and in various types of malignancy, including renal cell carcinoma $(9,10)$. Previous studies have indicated that TILs serve a key role in the carcinogenesis of breast cancer $(11,12)$. The assessment of the extent of lymphocyte infiltration in the cancerous tissue of patients with breast cancer using hematoxylin and eosin (H\&E) staining demonstrated that it exhibits predictive and prognostic value in patients with triple-negative breast cancer 
(TNBC), and in those with a HER2-positive status (13-15). It has been demonstrated that patients with TNBC with a higher proportion of stromal TILs at diagnosis exhibit an improved prognosis following the administration of anthracycline-based chemotherapy (13). Similar therapeutic effects were observed in patients with breast cancer with positive HER-2 status during transtuzumab treatment (14). These studies confirm that TILs are notable prognostic and predictive factors in various types of malignancy; therefore, the aim of the present study was to perform a quantitative morphological evaluation of the TIL populations in the stromal and intraepithelial cancer structures in the invasive front and the center of the tumor mass in patients with colorectal cancer (CRC), in correlation with clinicopathological features and disease-free-survival (DFS).

\section{Materials and methods}

Patients. The present study included 160 patients diagnosed with CRC (males, 88; females, 56) who underwent surgery in the Department of Oncological Surgery, Comprehensive Cancer Center (Bialystok, Poland) between April 2014 and December 2016. The mean age was 67.5 years, including 40 patients $<60$ and 120 patients $>60$ years old. The majority of patients presented with the symptoms of abdominal ache, anemia, rectal bleeding, constipation, diarrhea, vomiting and anorexia. A history of malignant neoplasm was noted for $16 / 160$ patients. In the majority of cases, patients were additionally receiving treatment for hypertension, type II diabetes, osteoarthritis and coronary heart disease. Colonoscopy examination to confirm the presence of cancerous tissue in the intestine wall was performed in 62 cases. On macroscopic examination of the surgical specimens, cancerous tissue was limited to the gut wall in 69 cases, and exceeded the wall focally in 17 cases and continuously in 74 cases. During diagnostic examination, polyps were identified in 30 cases; the total number of polyps was between 1 and 10. They were histopathologically classified as tubular (15 cases), tubulo-villous (10 cases) and others (5 cases).

All patients received routine diagnostic tests, including basic diagnostic laboratory tests (morphological tests and lipid profiles), electrocardiography, spirometry, arterial blood gasometric study and X-ray and computerized tomography (CT) imaging of the chest. Clinical efficiency was evaluated with the response criteria of the Eastern Cooperative Oncology Group (16). The clinical stage of CRC was evaluated according to the Tumor Node Metastasis (TNM) classification (17) and the Duke's staging systems (18). Patients diagnosed with neoplasms in the rectum received preoperative therapy $(n=53)$, including radiotherapy $(n=39)$, chemotherapy $(n=7)$ and radio-chemotherapy $(n=7)$. For patients receiving radiotherapy, a dose of 25 Gy was administered in fractions of 5 Gy over one week to the pelvic area. Preoperatively, patients with tumors situated in other regions did not receive inflammatory or immunosuppressive therapy. The response to preoperative therapy was estimated according to the Response Evaluation Criteria in Solid Tumors criteria (19).

The present study was performed in accordance with the Declaration of Helsinki for Human Experimentation, and the protocol was approved by the Bioethics Committee of the Medical University of Bialystok (approval no.
R-I-002/352/2016). Written informed consent was obtained from all participants.

Histopathological examination of CRC tumor tissue. Sections (4 $\mu \mathrm{m}$-thick) were cut from paraffin blocks and stained with H\&E (cat no. 468802128; POCH S.A.; Avantor Performance Materials Poland, Gliwice, Poland) according to the manufacturer's protocol. Slides were deparaffinized in a heating oven at $60^{\circ} \mathrm{C}$ for $5 \mathrm{~min}$. Subsequently, slides were rehydrated in xylene ( 3 washes at $10 \mathrm{~min}$, respectively) and in a gradual concentration of ethanol $(100,95,85$, and $75 \%$ for $1 \mathrm{~min}$ at each concentration). Routine histopathological assessment of the sections was performed to determine the type of tumor growth, tumor size, histological type, percentage of mucinous components, grade of malignancy, TNM and Duke's stages. Venous, lymphatic and perineural invasions were also analyzed, and the characteristic features of lymph node invasion, including the number of resected and invaded lymph nodes, the presence of micro- and macrometastases, invasion of the pouch lymph node, presence of the distant metastases and their size were examined. The presence of deposits, and their number and size, were also assessed (20).

The tumor stroma ratio (TSP) was also determined, as previously described by Huijbers et al (21). The analysis was performed in the most invasive tumor area of each slide using x 25 or x 50 magnification. The tumor and stromal tissues were identified and subsequently viewed at x100 magnification. Tumor cells were required to be present at all borders of the image field; necrotic areas and mucinous components were excluded. The TSP ratio was defined as a percentage of tumor structure to stroma per image field. The TSP ratio was divided into two groups: Stroma-high, $>50 \%$; and stroma-lo, $\leq 50 \%$. Tumor budding was analyzed as described by Morodomi et al (22). The extent of the inflammatory cell reaction in the invasive front of the tumor and the center of the tumor mass was also observed and classified according the Klintrup-Makinen criteria (23). The extent of necrosis and fibrosis in the central tumor was evaluated according to Richards et al (24) and graded as: Absent, none; focal, $<10 \%$ of tumor area; moderate, $10-30 \%$; or extensive, $>30 \%$. Crohn's-like aggregates of lymphocytes (CRL) were evaluated in the basis of Väyrynen criteria (25). Histological categorization of fibrotic cancer stroma was performed based on the Ueno et al criteria (26).

Examination of TILs. Tissue material obtained from routine histopathological diagnosis was stained with $\mathrm{H} \& \mathrm{E}$ and used to assess two types of TILs populations located in the stroma and intraepithelial cancer structures of the invasive front and center of the tumor by light microscopy (magnification, x200-400; Leica DM6 B; KAWA.SKA, Sp. z o.o., Piaseczno, Poland). The analysis was evaluated by two independent pathologists who were blinded to the clinical information.

TILs in the stroma were identified according to recommendations by the International TILs Working Group, 2014 (11). They were determined as a percentage of mononuclear inflammatory cells in the total intratumoral or stromal area as counted in 5 high power fields (HPF; magnification, $x 200-400$ ), in the invasive front and in the center of the tumor, with the exception of tumor areas with crush artifacts, necrosis or regressive 
hyalinization. The invasive front of the tumor was defined as the most progressed cancer cells on the advanced edge of the tumor. For statistical analysis, three levels of infiltration in the stroma TILs were determined: 1 , weak $(0-10 \%$ of stromal TILs); 2, moderate (20-40\% of stromal TILs); and 3, strong (50-90\% of stromal TILs). The study population was divided into two groups: 1, level 1; and 2, level 2 or 3.

TILs presenting in the inside of the cancer tubes of the tumor were counted in $5 \mathrm{HPF}$ in the invasive front and in the center of the tumor, with the exception of apoptotic bodies, and the mean number per adenocarcinoma structure was determined. For statistical analysis, TILs in the inside of the cancer tubes were divided into two groups: 0, absent (no TILs); and 1 , present ( $\geq 1$ TILs in intraepithelial tube).

Follow-up. Patients were followed-up for 2-2.5 years. They were monitored with the measurement of carcinoembryonic antigen and carbohydrate antigen 19-9 levels, physical examination, colonoscopy or/and radiological imaging including $\mathrm{CT}$ of the chest, abdomen, and pelvis, bone scan and positron emission tomography scans. Local and distant recurrences were defined as pathological evidence of tumor emergence in the region of the anastomosis, i.e., local recurrence, or/and present outside of the primary tumor at other sites, i.e., distant recurrence, including in the liver, lungs, bone and brain, confirmed by the aforementioned techniques.

Statistical analysis. Statistical analysis was conducted using STATISTICA 10.0 software (Statsoft Polska Sp. z o.o., Cracow, Poland). The Mann-Whitney U-test was used compare between groups. Correlations between the parameters were evaluated by Spearman's correlation coefficient tests. DFS time was calculated from the date of diagnosis to the date of disease progression, including local or distant relapse. DFS rate was estimated using the Kaplan Meier method and the survival curves were compared using log-rank tests. Multivariate Cox proportional hazards models were used to estimate hazard ratios (HR). $\mathrm{P}<0.05$ was considered to indicate a statistically significant difference.

\section{Results}

Histopathological examination. The CRC tumor was localized at the right side of the colon in 20 cases, transverse colon in 14, left side of the colon in 15, sigmoid in 29 and in the rectum in 82 cases. The tumors presented as expanding ulcerative masses in the wall of the colon in 133 cases, whereas they developed as an infiltrative lesion mass attached to the intestinal lumen in 27 cases. The mean tumor size was $3.5 \pm 1.69 \mathrm{~cm}$ (range, 1.5-8.0 cm). Tumors were divided into three groups according to size: $<2.5(\mathrm{n}=27), 2.5-5.0(\mathrm{n}=106)$ and $>5.0 \mathrm{~cm}$ $(n=27)$. Non-mucinous type adenocarcinoma was diagnosed in 130 cases, and there were 30 cases of mucin-producing tumors. Partim mucinous type adenocarcinoma was defined as a malignant tumor mass with classical glandular-like structures and a mucinous component that ranged from $10-50 \%$ of all histological features. For statistical analysis, mucin-producing tumors were classified into two groups: Mucinous component range, $10-30 \%(n=15)$; and mucinous component range, $31-50 \%(n=15)$. According to pTNM stage, there were 42 stage I tumors, 31 in stage II, 69 in stage III and 18 in stage IV; this was similar to their Duke stage classification. Patients responded to preoperative radiotherapy in part (partial response, PR; $n=27$ ) and insufficiently but without disease progression (stable disease, $S D ; n=26$ ). No patients achieved complete response.

The local and distant progression of the disease was analyzed by assessment of metastatic histological features. Tumors invaded the submucosa in 3 cases, were limited to the muscularis propria in 62 cases, infiltrated through the muscularis propria into the pericolorectal tissues in 91 and penetrated to the surface of the visceral peritoneum and invaded other organs in 4 cases. The invasion of blood vessels was present in 46 patients. Tumors had spread to lymphatic vessels in 38 patients and the space surrounding a nerve in 17 patients. The mean number of removed local lymph nodes per patient was 15. For statistical analysis, the number of resected regional lymph nodes was divided into 3 groups: Under 5 $(n=14)$; between 5-10 $(n=29)$; and $>10(n=116)$. Lymph node involvement was observed in 79 cases. There were 49 patients with $<5$ lymph nodes with metastases, and 26 cases with $>5$ lymph nodes with metastases. The mean size of metastatic tumors within local lymph nodes was $2.26 \mathrm{~mm}$. Metastases of the lymph nodes were grouped as: Micro-(diameter $<2.0 \mathrm{~mm} ; \mathrm{n}=27$ ); and macro-invasion (diameter $\geq 2.0 \mathrm{~mm}$; $\mathrm{n}=52$ ). Tumors infiltrating the pouch of lymph nodes were diagnosed in 68 cases. Metastases to distant organs (primarily the liver) were observed in 17 cases. For statistical analysis, distant metastases were grouped by size: $<10 \mathrm{~mm}(\mathrm{n}=11)$; and $\leq 10 \mathrm{~mm}(\mathrm{n}=6)$. Other cases with distant metastases exhibited multifocal lesions in the liver tissues; these patients were not included in the metastatic grouping. Tumor deposits were defined as tumor clusters of cancer cells located in the pericolic/perirectal adipose tissue without lymphocyte aggregates that were macroscopically classified to lymph nodes. Cancer nodules/deposits were present in 27 cases (range, 1-4). On average, deposits measured $0.695 \mathrm{~mm}$ in size. For statistical analysis, two groups of deposit size were defined: $<2.5(n=10)$ and $\geq 2.5 \mathrm{~mm}(\mathrm{n}=17)$.

In addition, the morphological features of CRC were analyzed in detail. There were 66 patients with tumors with high stroma ratios, and 94 patients with tumors with low ratios. The majority of cases with a high stroma ratio had received pre-operative treatment. Tumor budding was observed in 66 cases (range, 5-20 per patient). The number of patients with weak, moderate and strong evidence of inflammatory cell infiltration in the invasive front of the tumor were 66, 48 and 26, respectively. Inflammatory cells in the center of tumor mass infiltrated to a weak degree in 76 , moderate in 51 and strong in 22 cases. Crohn's-like aggregates of lymphocytes were identified in 42 cases. The degree of necrosis was focal, in 61 cases, moderate in 36 cases and extensive in 18 cases. Fibrosis was focal in 72 cases, moderate in 43 and extensive in 34 cases. The tumors were classified according to the maturation of fibrotic stroma. A total of 12 tumors exhibited immature stroma, 91 intermediate stroma and 57 mature stroma.

TILs in CRC. The presence of TILs inside of cancer structures was observed in 123 patients in the invasive front of the tumor and 121 patients in the center of the tumor 
Table I. Assessment of TILs in stroma and in the inside of the cancer tubes in colorectal cancer tissue.

A, Intraepithelial TILs

\begin{tabular}{lccc}
\hline Location & No lymphocytes & $\geq 1$ lymphocytes & P-value \\
\hline Invasive front of tumor & 32 & 128 & 0.179 \\
Main mass of tumor & 36 & 124 & \\
\hline
\end{tabular}

B, Stromal TILs

\begin{tabular}{lcccc}
\hline Location & Weak infiltration & Moderate infiltration & Strong infiltration $^{\text {P-value }^{\mathrm{a}}}$ \\
\hline Invasive front of tumor & 91 & 44 & 25 & 0.474 \\
Main mass of tumor & 85 & 49 & 26
\end{tabular}

${ }^{a}$ Mann-Whitney U-test. TILs, tumor-infiltrating lymphocytes.

(1-7 lymphocytes/1 adenocarcinoma tube). The levels of infiltration of stromal TILs in the front of the tumor was weak in 91 cases, moderate in 44 and severe in 25 cases, while infiltration of stromal TILs into the center of the tumor was weak in 85 patients, moderate in 49 and severe in 26 patients (Table I and Fig. 1).

Intraepithelial TILs are associated with the inflammatory response and maturation of fibrotic stroma. The infiltration of intraepithelial TILs in the invasive front of cancer was positively correlated with inflammatory cell infiltrate in the invasive front $(\mathrm{R}=0.178, \mathrm{P}=0.033)$ and in the center of the tumor mass $(\mathrm{R}=0.195, \mathrm{P}=0.019)$, Crohn's like aggregates lymphocyte $(\mathrm{R}=0.264, \mathrm{P}=0.001)$ and maturation of fibrotic stroma $(\mathrm{R}=0.252, \mathrm{P}=0.002)$. Intraepithelial TILs in the center of CRC tumors were positively correlated with the inflammatory response in the center of the tumor mass $(\mathrm{R}=0.186$, $\mathrm{P}=0.026)$ and Crohn's-like lymphocyte aggregates $(\mathrm{R}=0.198$, $\mathrm{P}=0.017)$. Results were summarized in Tables II and III.

Stromal TILs correlate with histopathological features of tumor progression. Statistical analysis demonstrated that stromal TILs present in the invasive tumor front were negatively correlated with blood vessel $(\mathrm{R}=-0.200, \mathrm{P}=0.016)$, lymph vessel $(\mathrm{R}=-0.224, \mathrm{P}=0.007)$ and perineural invasion $(\mathrm{R}=-0.174, \mathrm{P}=0.036)$, lymph node involvement $(\mathrm{R}=-0.166$, $\mathrm{P}=0.047)$ and infiltration of the lymph node pouch $(\mathrm{R}=-0.170$, $\mathrm{P}=0.041)$. Stromal TILs observed in the center of the tumor were correlated with the TNM $(\mathrm{R}=-0.170, \mathrm{P}=0.041)$ and Duke's stage $(\mathrm{R}=-0.190, \mathrm{P}=0.022)$, invasion of the lymphatic vessels $(\mathrm{R}=-0.186, \mathrm{P}=0.025)$ and the presence of distant metastases $(\mathrm{R}=-0.178, \mathrm{P}=0.032)$ and their diameter $(\mathrm{R}=-0.188, \mathrm{P}=0.034)$. Additionally, stromal TILs in center of the tumor were correlated with TSP ratio $(\mathrm{R}=-0.204, \mathrm{P}=0.019)$ and maturation of fibrotic stoma $(\mathrm{R}=0.202, \mathrm{P}=0.015)$. In localization, stromal TILs in the invasive front $(\mathrm{R}=0.631, \mathrm{P}<0.001)$ and the tumor mass $(\mathrm{R}=0.445, \mathrm{P}<0.001)$ were associated with inflammatory cell infiltration in the invasive front; stromal TILs were also associated with inflammatory cell infiltration in the center of the tumor (invasive front, $\mathrm{R}=0.318, \mathrm{P}<0.001$; tumor mass,
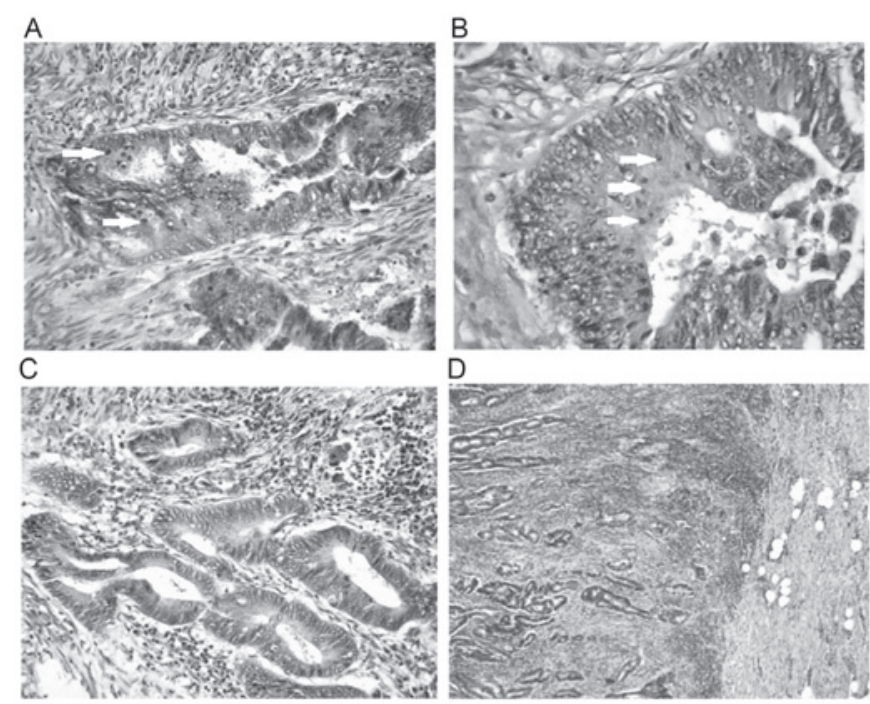

Figure 1. Intraepithelial TILs in tumor tissue samples. (A) Individual TILs in the invasive front and (B) numerous TILs in the primary mass of the tumor were identified (white arrows). (C) A number of patients did not exhibit intraepithelial TILs, whereas (D) stromal TILs were observed in the invasive front of the tumor in the majority of patients with colorectal cancer. TILs, tumor-infiltrating lymphocytes.

$\mathrm{R}=0.658, \mathrm{P}<0.001)$ and Crohn's like aggregates lymphocyte $(\mathrm{R}=0.205, \mathrm{P}=0.014)$. The results were provided in Table IV.

DFS time and prognostic factors in CRC. The mean DFS time was 12.1 months for all patients. Patients who lacked intraepithelial TILs at the invasive front of the tumor exhibited a shorter DFS time $(\mathrm{P}=0.050 ; \mathrm{HR}=1.03)$. DFS time was shorter in patients without intraepithelial TILs in the center of the primary tumor mass $(\mathrm{P}=0.049$; $\mathrm{HR}=1.45$; Fig. $2 \mathrm{~A}$ and $\mathrm{B})$. Stromal TILs in the invasive front and center of the tumor mass were not associated with DFS time in patients with CRC $(\mathrm{P}=0.051, \mathrm{HR}=1.12 ; \mathrm{P}=0.378, \mathrm{HR}=1.01$, respectively; Fig. 2C and D). Factors identified to be predictive of DFS time from univariate Cox regression analysis included: TNM stage $(\mathrm{P}=0.003)$, pre-operative treatment $(\mathrm{P}=0.040)$, venous 
Table II. Correlation between TILs in stroma and in the inside of the cancer tubes and clinical features of colorectal cancer.

\begin{tabular}{|c|c|c|c|c|c|c|c|c|c|}
\hline \multirow{3}{*}{$\frac{\text { Variables }}{\text { Total }}$} & \multirow{3}{*}{$\frac{\mathrm{n}}{160}$} & \multicolumn{4}{|c|}{ Intraepithelial TILs } & \multicolumn{4}{|c|}{ Stromal TILs } \\
\hline & & \multicolumn{2}{|c|}{ Invasive front } & \multicolumn{2}{|c|}{ Tumor mass } & \multicolumn{2}{|c|}{ Invasive front } & \multicolumn{2}{|c|}{ Tumor mass } \\
\hline & & $\mathrm{R}$ & P-value ${ }^{a}$ & $\mathrm{R}$ & P-value ${ }^{a}$ & $\mathrm{R}$ & P-value ${ }^{a}$ & $\mathrm{R}$ & P-value ${ }^{a}$ \\
\hline Age (years) & & NS & NS & NS & NS & NS & NS & NS & NS \\
\hline$<60$ & 40 & & & & & & & & \\
\hline$>60$ & 120 & & & & & & & & \\
\hline Sex & & NS & NS & NS & NS & NS & NS & -0.191 & 0.022 \\
\hline Female & 64 & & & & & & & & \\
\hline Male & 96 & & & & & & & & \\
\hline Localization & & NS & NS & NS & NS & NS & NS & NS & NS \\
\hline Right-side & 20 & & & & & & & & \\
\hline Transverse & 14 & & & & & & & & \\
\hline Left-side & 15 & & & & & & & & \\
\hline Sigmoid & 29 & & & & & & & & \\
\hline Rectum & 82 & & & & & & & & \\
\hline Tumor growth & & NS & NS & NS & NS & NS & NS & NS & NS \\
\hline Expanding & 133 & & & & & & & & \\
\hline Infiltration & 27 & & & & & & & & \\
\hline Tumor size (cm) & & NS & NS & NS & NS & NS & NS & NS & NS \\
\hline$<2.5$ & 27 & & & & & & & & \\
\hline $2.5-5.0$ & 106 & & & & & & & & \\
\hline$>5.0$ & 27 & & & & & & & & \\
\hline \multicolumn{10}{|l|}{ Tumor node metastasis stage } \\
\hline 1 & 42 & NS & NS & NS & NS & NS & NS & -0.170 & 0.041 \\
\hline 2 & 31 & & & & & & & & \\
\hline 3 & 69 & & & & & & & & \\
\hline 4 & 18 & & & & & & & & \\
\hline Duke's stage & & NS & NS & NS & NS & NS & NS & -0.190 & 0.022 \\
\hline A & 39 & & & & & & & & \\
\hline $\mathrm{B}$ & 35 & & & & & & & & \\
\hline $\mathrm{C}$ & 69 & & & & & & & & \\
\hline $\mathrm{D}$ & 17 & & & & & & & & \\
\hline Adenocarcinoma type & & NS & NS & NS & NS & NS & NS & NS & NS \\
\hline Partim mucinous & 30 & & & & & & & & \\
\hline Nonmucinous & 130 & & & & & & & & \\
\hline $\begin{array}{l}\text { Percentage of mucinous, } \% \\
\text { component }\end{array}$ & & NS & NS & NS & NS & NS & NS & NS & NS \\
\hline $10-30$ & 15 & & & & & & & & \\
\hline $30-50$ & 15 & & & & & & & & \\
\hline Grade of malignancies & & NS & NS & NS & NS & NS & NS & NS & NS \\
\hline 2 & 148 & & & & & & & & \\
\hline 3 & 12 & & & & & & & & \\
\hline Preoperative treatment & & NS & NS & NS & NS & NS & NS & NS & NS \\
\hline Yes & 53 & & & & & & & & \\
\hline No & 107 & & & & & & & & \\
\hline
\end{tabular}


Table II. Continued.

\begin{tabular}{|c|c|c|c|c|c|c|c|c|c|}
\hline \multirow{3}{*}{$\frac{\text { Variables }}{\text { Total }}$} & \multirow{3}{*}{$\frac{\mathrm{n}}{160}$} & \multicolumn{4}{|c|}{ Intraepithelial TILs } & \multicolumn{4}{|c|}{ Stromal TILs } \\
\hline & & \multicolumn{2}{|c|}{ Invasive front } & \multicolumn{2}{|c|}{ Tumor mass } & \multicolumn{2}{|c|}{ Invasive front } & \multicolumn{2}{|c|}{ Tumor mass } \\
\hline & & $\mathrm{R}$ & P-value ${ }^{a}$ & $\mathrm{R}$ & P-value ${ }^{a}$ & $\mathrm{R}$ & P-value ${ }^{a}$ & $\mathrm{R}$ & P-value ${ }^{a}$ \\
\hline Treatment response & & NS & $\mathrm{NS}$ & NS & NS & NS & $\mathrm{NS}$ & NS & NS \\
\hline $\mathrm{SD}$ & 26 & & & & & & & & \\
\hline PR & 27 & & & & & & & & \\
\hline
\end{tabular}

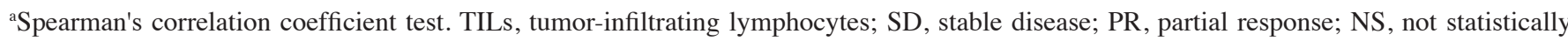
significant.

invasion $(\mathrm{P}=0.016)$, lymph node metastasis $(\mathrm{pN} ; \mathrm{P}=0.001)$ number of metastatic lymph nodes $(\mathrm{P}=0.041)$ and distant metastasis ( $\mathrm{pM} ; \mathrm{P}=0.012)$. According to the multivariate Cox proportional model, TNM stage $(\mathrm{P}<0.001)$, venous invasion $(\mathrm{P}<0.001)$, lymph node metastasis $(\mathrm{P}=0.005)$ and number of metastatic lymph nodes $(\mathrm{P}=0.046)$ were independent factors for DFS time in CRC (Table V).

\section{Discussion}

CRC, malignant melanoma, kidney, lung and pancreatic cancer develop independent of pathogens; however, these types of cancer are increasing in prevalence in the immunocompromised population (27). Inflammatory cells involved in the innate response (NK cells, immature $\mathrm{T}$ lymphocytes, macrophages) serve a key role in anti-tumor defense; cells associated with the acquired response, including antigen-presenting cells such as $\mathrm{CD}^{+}$and $\mathrm{CD} 45 \mathrm{RO}^{+} \mathrm{T}$ cells, are associated with CRC progression (28). It was previously demonstrated that $50 \%$ of $\mathrm{T}$ and $\mathrm{B}$ immunodeficient mice spontaneously developed tumors in the colon and lung, with $80 \%$ of the tumors additionally exhibiting resistance to interferon- $\gamma$ (29). A further study indicated that tumor-infiltrating lymphocytes serve a significant role in antitumor immune responses, and provide a novel potential prognostic and predictive indicator of CRC (30).

The study by Jass et al (31) was the first attempted classification of inflammatory lymphocytic infiltrate in CRC, which is based on a 4-point scale assessment of the intensity of lymphocyte infiltration. Then, Ogino et al (32) proposed that the evaluation of the lymphocytic response should include four elements: Crohn's-like reaction; peritumoral reaction; intratumoral periglandular reaction; and density of TILs. Concomitantly, Klintrup et al (23) analyzed inflammatory cell reaction in the invasive margin and generated a classification system: 0 was defined as no increase in inflammatory cell infiltrate; 1 was defined as mild or patchy increases; 2 denoted a prominent inflammatory reaction with specific evidence of cancer cell destruction; and 3 denoted florid 'cup-like' inflammatory infiltrate. The present study aimed to provide a detailed morphological evaluation of the two types of TILs populations located in the stromal and intraepithelial cancer structures in the invasive front and the center of the tumor in patients with CRC. The presence of TILs was identified in the inside of the cancer tubes of the invasive front of tumor and in the center of the primary tumor in $80 \%$ of cases. The assessment of stromal TILs at the invasive front and center of the tumors confirmed that the degree of infiltration was low in $~ 50 \%$ of cases, moderate in $28 \%$ of cases and high in $14 \%$ of cases. It has been demonstrated that intraepithelial TILs are activated and permanently bind tumor parenchyma only in the presence of a tumor-associated antigen; single tumor cell antigens activate TILs and generate cytotoxic reactions, and the degree of their stimulation depends on their clone (33). In the case of stromal TILs, these cells are stimulated by an APC-lymphocyte sequence. The strength, characteristics and selectivity of the response by stromal TILs clones depends on the type of antigen on the tumor cell (11). The evaluation of the presence of intraepithelial and stromal TILs may assist in determining the degree of involvement of the immune response in CRC.

The invasive front of the tumor is the first line of defense against cancer metastasis. If it does not have adequate immune stimulation, structures in the tumor including the blood and lymphatic vessels, and perineural spaces, may allow the invasion of selected clones of cancer cells into the surrounding tissue and to other organs (33). In the present study, a decline in TILs in the stroma of tumors with involvement of blood vessel, lymphatic tubes, perineural space and the presence of lymph node metastases was observed, which confirmed they are the main population of inflammatory cells that are responsible for the immune response. the marked part of the cells generating immune responses. The results of the present study were consistent with the observations of Huh et al (34), in which a low TIL grade was identified to be correlated with perineural invasion. Additionally, Pagès et al (35) demonstrated that the presence of a high degree of immune infiltrate at the invasive margin was associated with a lack of the characteristics of early metastatic processes, including vascular emboli, lymphatic invasion and perineural invasion in CRC. Pagès et al (36) also confirmed that the decrease in lymphatic reaction against $\mathrm{CRC}$ cells was associated with positive status of lymph node involvement. Conversely, Perez et al (37) observed a statistically significant correlation between TILs grade and vascular emboli, lymphatic and perineural invasion in rectal cancer; the number and activation of stromal TILs in the invasive front of the lesions were correlated with the ability 
Table III. Correlation between TILs in stroma and in the inside of the cancer tubes and parameters of disease progression.

\begin{tabular}{|c|c|c|c|c|c|c|c|c|c|}
\hline \multirow[b]{3}{*}{ Variables } & \multirow{3}{*}{$\frac{\mathrm{n}}{160}$} & \multicolumn{4}{|c|}{ Intraepithelial TILs } & \multicolumn{4}{|c|}{ Stromal TILs } \\
\hline & & \multicolumn{2}{|c|}{ Invasive front } & \multicolumn{2}{|c|}{ Tumor mass } & \multicolumn{2}{|c|}{ Invasive front } & \multicolumn{2}{|c|}{ Tumor mass } \\
\hline & & $\mathrm{R}$ & P-value ${ }^{a}$ & $\mathrm{R}$ & P-value & $\mathrm{R}$ & P-value ${ }^{a}$ & $\mathrm{R}$ & P-value \\
\hline pT stage & & NS & NS & NS & NS & NS & NS & NS & NS \\
\hline 1 & 3 & & & & & & & & \\
\hline 2 & 62 & & & & & & & & \\
\hline 3 & 91 & & & & & & & & \\
\hline 4 & 4 & & & & & & & & \\
\hline Venous invasion & & NS & NS & NS & NS & -0.200 & 0.016 & NS & NS \\
\hline Absent & 113 & & & & & & & & \\
\hline Present & 46 & & & & & & & & \\
\hline Lymphatic invasion & & NS & NS & NS & NS & -0.224 & 0.007 & -0.186 & 0.025 \\
\hline Absent & 122 & & & & & & & & \\
\hline Present & 38 & & & & & & & & \\
\hline Perineural invasion & & NS & NS & NS & NS & NS & NS & NS & NS \\
\hline Absent & 143 & & & & & & & & \\
\hline Present & 17 & & & & & & & & \\
\hline $\begin{array}{l}\text { No. of removed } \\
\text { lymph nodes }\end{array}$ & & NS & NS & NS & NS & NS & NS & NS & NS \\
\hline$<5$ & 14 & & & & & & & & \\
\hline $5-10$ & 29 & & & & & & & & \\
\hline$>10$ & 117 & & & & & & & & \\
\hline Lymph node metastasis & & NS & NS & NS & NS & -0.166 & 0.047 & NS & NS \\
\hline Absent & 81 & & & & & & & & \\
\hline Present & 79 & & & & & & & & \\
\hline $\begin{array}{l}\text { Type of lymph node } \\
\text { metastasis }\end{array}$ & & NS & NS & NS & NS & NS & NS & NS & NS \\
\hline Micro & 27 & & & & & & & & \\
\hline Macro & 52 & & & & & & & & \\
\hline $\begin{array}{l}\text { No. of metastatic } \\
\text { lymph nodes }\end{array}$ & & NS & NS & NS & NS & NS & NS & NS & NS \\
\hline$<5$ & 49 & & & & & & & & \\
\hline$>5$ & 26 & & & & & & & & \\
\hline $\begin{array}{l}\text { Lymph node pouch } \\
\text { invasion }\end{array}$ & & NS & NS & NS & NS & -0.170 & 0.041 & NS & NS \\
\hline Absent & 11 & & & & & & & & \\
\hline Present & 68 & & & & & & & & \\
\hline Distant metastasis & & NS & NS & NS & NS & NS & NS & -0.178 & 0.032 \\
\hline Absent & 143 & & & & & & & & \\
\hline Present & 17 & & & & & & & & \\
\hline $\begin{array}{l}\text { Distant metastasis } \\
\text { size, } \mathrm{mm}\end{array}$ & & NS & NS & NS & NS & NS & NS & -0.178 & 0.034 \\
\hline$<10$ & 11 & & & & & & & & \\
\hline$>10$ & 6 & & & & & & & & \\
\hline Tumor deposits & & NS & NS & NS & NS & NS & NS & NS & NS \\
\hline Absent & 133 & & & & & & & & \\
\hline Present & 27 & & & & & & & & \\
\hline
\end{tabular}


Table III. Continued.

\begin{tabular}{|c|c|c|c|c|c|c|c|c|c|}
\hline \multirow[b]{3}{*}{ Variables } & \multirow{3}{*}{$\frac{\mathrm{n}}{160}$} & \multicolumn{4}{|c|}{ Intraepithelial TILs } & \multicolumn{4}{|c|}{ Stromal TILs } \\
\hline & & \multicolumn{2}{|c|}{ Invasive front } & \multicolumn{2}{|c|}{ Tumor mass } & \multicolumn{2}{|c|}{ Invasive front } & \multicolumn{2}{|c|}{ Tumor mass } \\
\hline & & $\mathrm{R}$ & P-value ${ }^{a}$ & $\mathrm{R}$ & P-value ${ }^{a}$ & $\mathrm{R}$ & P-value ${ }^{a}$ & $\mathrm{R}$ & P-value \\
\hline $\begin{array}{l}\text { Size of tumor } \\
\text { deposits, mm }\end{array}$ & & NS & NS & NS & NS & NS & NS & NS & NS \\
\hline$<2.5$ & 10 & & & & & & & & \\
\hline$>2.5$ & 17 & & & & & & & & \\
\hline
\end{tabular}

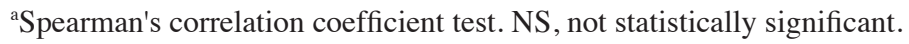

A Intraepithelial TILs in the invasive front of tumor

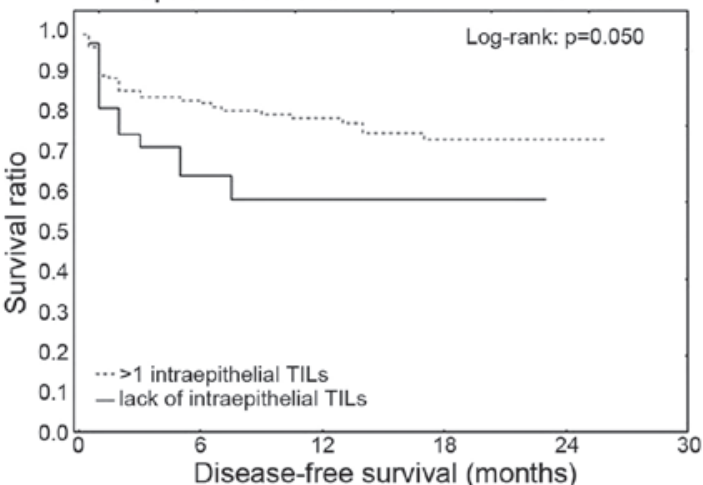

C Stromal TILs in the invasive front of tumor

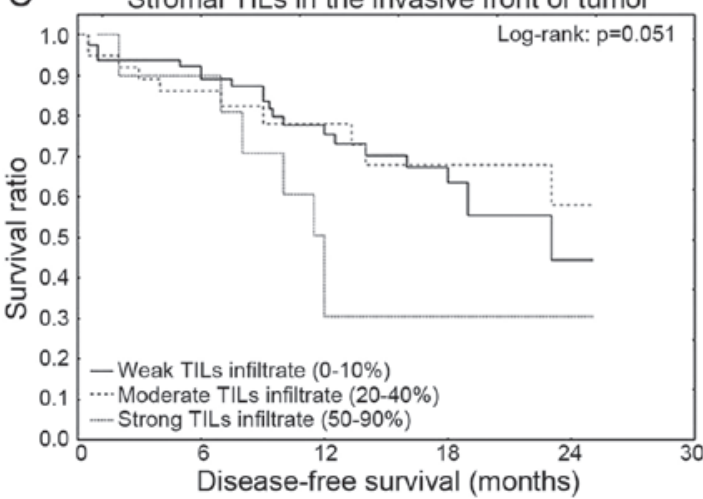

B Intraepithelial TILs in the center of tumor

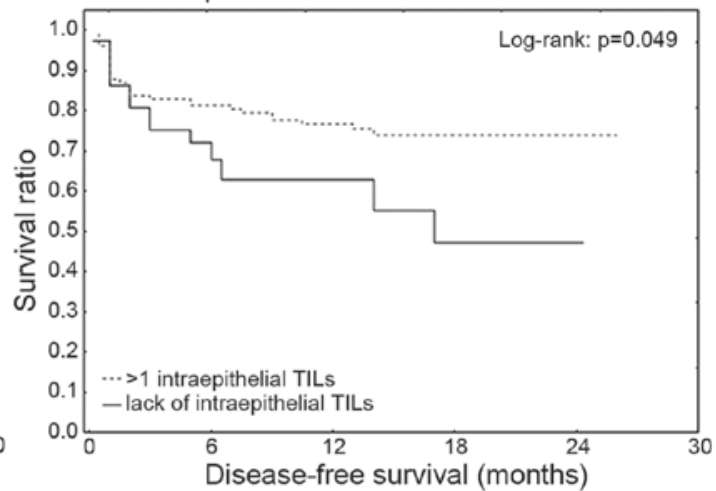

D

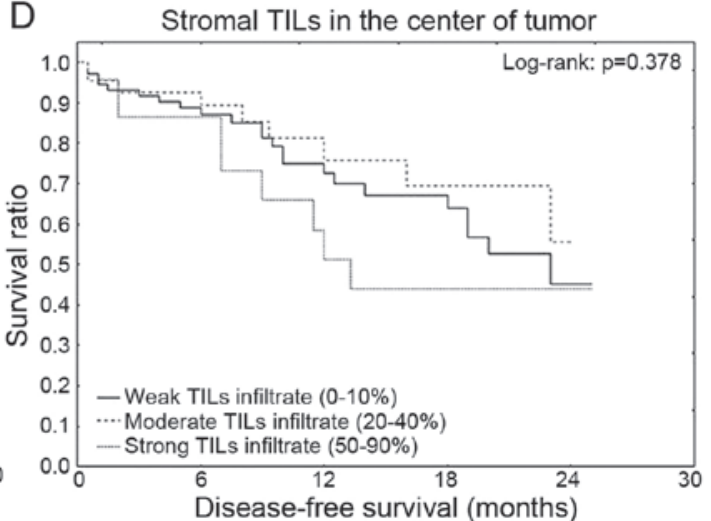

Figure 2. Postoperative disease-free survival curves of patients with colorectal cancer. Kaplan Meier curves for patients with intraepithelial TILs in (A) the invasive front and (B) the center of the mass of the tumor, and (C) stromal TILs in the invasive front and (D) the center of the mass of the tumor. TILs, tumor-infiltrating lymphocytes.

to recognize tumor specific antigens and the lymphocytic infiltration of cells inside the tumor tubes. These observations confirmed the results regarding the stromal TILs, in which a positive correlation between intraepithelial TILs and localization of inflammatory cell infiltrate was observed. Additional previous studies have also reported this association $(28,38)$.

In addition, a weak inflammatory response in the invasive front of the tumor affects the development of the response and organization of TILs in the center of the primary tumor stroma, as confirmed by the correlation data of the present study. A low proportion of stromal TILs in the center of the tumor was associated with an increase in the severity of CRC, as classified by Dukes and TNM staging systems. The inefficient inflammation of TILs in the center of the primary tumor was conducive to the metastasis of cancer cells to distant organs and potentially determined the tumor size. Wagner et al (39) demonstrated that the presence of TILs in CRC metastases to the liver depends on the migration and activation of helper $\mathrm{CD}^{+} \mathrm{T}$ cells, and the stimulation and cytotoxic properties of $\mathrm{CD}^{+} \mathrm{T}$ cells. Also, Schweiger et al (40) confirmed a significant effect of TILs on the likelihood of CRC metastasis to the lung.

Stromal TILs are likely to be the most important factor for the formation and maturity of the tumor microenvironment (41). The present study demonstrated that they are a 
Table IV. Correlation between TILs in stroma and in the inside of the cancer tubes and morphological variables of colorectal cancer.

\begin{tabular}{|c|c|c|c|c|c|c|c|c|c|}
\hline \multirow[b]{3}{*}{ Variables } & \multirow{3}{*}{$\frac{\mathrm{n}}{160}$} & \multicolumn{4}{|c|}{ Intraepithelial TILs } & \multicolumn{4}{|c|}{ Stromal TILs } \\
\hline & & \multicolumn{2}{|c|}{ Invasive front } & \multicolumn{2}{|c|}{ Tumor mass } & \multicolumn{2}{|c|}{ Invasive front } & \multicolumn{2}{|c|}{ Tumor mass } \\
\hline & & $\mathrm{R}$ & P-value & $\mathrm{R}$ & P-value & $\mathrm{R}$ & P-value & $\mathrm{R}$ & P-value ${ }^{a}$ \\
\hline Tumor stroma percentage, $\%$ & & NS & NS & NS & NS & NS & NS & -0.204 & 0.019 \\
\hline$<50$ & 94 & & & & & & & & \\
\hline$>50$ & 66 & & & & & & & & \\
\hline Tumor budding & & NS & NS & NS & NS & NS & NS & NS & NS \\
\hline Absent & 94 & & & & & & & & \\
\hline Present & 66 & & & & & & & & \\
\hline $\begin{array}{l}\text { Inflammatory cell infiltrate } \\
\text { in the invasive front } \\
\text { of tumor }\end{array}$ & & 0.178 & 0.033 & NS & NS & 0.631 & 0.000 & 0.445 & 0.000 \\
\hline Absent & 20 & & & & & & & & \\
\hline Weak & 66 & & & & & & & & \\
\hline Moderate & 48 & & & & & & & & \\
\hline Strong & 26 & & & & & & & & \\
\hline $\begin{array}{l}\text { Inflammatory cell infiltrate } \\
\text { in the center of tumor mass }\end{array}$ & & 0.195 & 0.019 & 0.186 & 0.026 & 0.318 & 0.000 & 0.658 & 0.000 \\
\hline Absent & 11 & & & & & & & & \\
\hline Weak & 76 & & & & & & & & \\
\hline Moderate & 51 & & & & & & & & \\
\hline Strong & 22 & & & & & & & & \\
\hline $\begin{array}{l}\text { Crohn's-like lymphocyte } \\
\text { aggregates }\end{array}$ & & 0.264 & 0.001 & 0.198 & 0.017 & 0.186 & 0.026 & 0.205 & 0.014 \\
\hline Absent & 118 & & & & & & & & \\
\hline Present & 42 & & & & & & & & \\
\hline Necrosis & & NS & NS & NS & NS & NS & NS & NS & NS \\
\hline Absent & 45 & & & & & & & & \\
\hline Focal & 61 & & & & & & & & \\
\hline Moderate & 36 & & & & & & & & \\
\hline Extensive & 18 & & & & & & & & \\
\hline Fibrosis & & NS & NS & NS & NS & NS & NS & NS & NS \\
\hline Absent & 11 & & & & & & & & \\
\hline Focal & 72 & & & & & & & & \\
\hline Moderate & 43 & & & & & & & & \\
\hline Extensive & 34 & & & & & & & & \\
\hline $\begin{array}{l}\text { Maturation of fibrotic } \\
\text { stroma }\end{array}$ & & 0.252 & 0.002 & NS & NS & NS & NS & 0.202 & 0.015 \\
\hline Immature & 12 & & & & & & & & \\
\hline Intermediate & 91 & & & & & & & & \\
\hline Mature & 57 & & & & & & & & \\
\hline
\end{tabular}

${ }^{\text {aS }}$ pearman's correlation coefficient test. NS, not statistically significant.

major source of diffuse inflammatory infiltrate in the invasive front and center of the primary tumor, although they may also be identified in lymphocytic aggregates similar to those in Crohn's disease. In addition, the increase in the number of
TILs resulted in an increase in the degree of stromal maturity. The degree of maturity of fibrotic cancer stroma consists of several elements: Matrix components; the cells responsible for matrix synthesis; and the inflammatory cells produce and 
Table V. Prognostic factors in patients with colorectal cancer.

\begin{tabular}{|c|c|c|c|}
\hline \multirow[b]{2}{*}{ Variables } & \multicolumn{2}{|c|}{ P-value } & \multirow{2}{*}{$\begin{array}{l}\text { Hazard ratio ( } 95 \% \\
\text { confidence interval) }\end{array}$} \\
\hline & Univariate & Multivariate & \\
\hline Age $(<60$ vs. $\geq 60)$ & 0.233 & - & $1.16(0.14-1.20)$ \\
\hline Sex (female vs. male) & 0.702 & - & $1.90(1.47-2.18)$ \\
\hline Tumor growth (expanding vs. infiltrate) & 0.760 & - & $0.82(0.09-1.21)$ \\
\hline Tumor size (<2.5 vs. $2.5-5$ vs. $>5 \mathrm{~cm})$ & 0.416 & - & $0.77(0.30-0.96)$ \\
\hline Tumor Node Metastasis stage (I-IV) & 0.003 & 0.000 & $2.09(0.13-5.35)$ \\
\hline Dukes stage (A-D) & 0.579 & - & $0.78(0.30-0.84)$ \\
\hline Adenocarcinoma type (non-mucinous vs. partim mucin) & 0.452 & - & $0.69(0.56-1.25)$ \\
\hline Malignancy grade (2 vs. 3 ) & 0.429 & - & $0.48(0.32-0.62)$ \\
\hline Preoperative treatment (yes vs. no) & 0.040 & 0.065 & $1.53(0.43-8.13)$ \\
\hline pT stage $(1-4)$ & 0.603 & - & $1.20(0.27-1.47)$ \\
\hline Venous invasion (yes vs. no) & 0.016 & 0.000 & $3.76(1.32-5.23)$ \\
\hline Lymphatic invasion (yes vs. no) & 0.432 & - & $0.57(0.42-1.25)$ \\
\hline Perineural invasion (yes vs. no) & 0.488 & - & $0.63(0.48-0.64)$ \\
\hline Number of removed lymph nodes (<5 vs. 5 -10 vs. $<10)$ & 0.453 & - & $0.80(0.29-1.32)$ \\
\hline Lymph node metastasis (yes vs. no) & 0.001 & 0.005 & $0.71(0.33-3.75)$ \\
\hline Type of lymph node metastasis (micro vs. macro) & 0.235 & - & $0.78(0.20-1.40)$ \\
\hline Number of metastatic lymph nodes (<5 vs. $\geq 5)$ & 0.041 & 0.046 & $3.50(0.62-3.97)$ \\
\hline Lymph node pouch invasion (yes vs. no) & 0.161 & - & $1.83(0.43-1.96)$ \\
\hline Distant metastasis (yes vs. no) & 0.012 & 0.099 & $0.58(0.32-2.70)$ \\
\hline Distant metastasis size (<10 vs $\geq 10 \mathrm{~mm})$ & 0.253 & - & $1.11(0.98-1.30)$ \\
\hline Tumor deposits (yes vs. no) & 0.815 & - & $1.06(0.27-1.57)$ \\
\hline Size of tumor deposits (<2.5 vs. $\geq 2.5 \mathrm{~mm})$ & 0.217 & - & $1.16(0.12-1.51)$ \\
\hline Intraepithelial TILs in the invasive front of tumor (present vs. absent) & 0.357 & - & $1.18(0.84-1.95)$ \\
\hline Intraepithelial TILs in the centrum of tumor mass (present vs. absent) & 0.201 & - & $1.23(1.07-1.63)$ \\
\hline Stromal TILs in the invasive front of tumor (weak vs. moderate vs. strong) & 0.169 & - & $0.63(0.33-0.88)$ \\
\hline Stromal TILs in the centrum of tumor mass (weak vs. moderate vs. strong) & 0.231 & - & $0.70(0.28-0.84)$ \\
\hline
\end{tabular}

TILs, tumor-infiltrating lymphocytes.

activate cytokines, including lymphocytes (40). It has been demonstrated that the maturation of fibrotic cancer stroma limits tumor aggressiveness and leads to an increase in spontaneous metastasis (42). As TILs significantly affect the composition and maturity of the stromal components to alter the potential for malignancy, the present study suggests that an assessment of TILs should be used in routine histopathological analysis in the future.

Previous studies indicated the TIL grade may exhibit an effect on the 5-year overall survival and DFS rates $(35,37)$. A decrease in TILs significantly shortened the 5-year overall survival and DFS in stage III tumors, and tumors of the rectum (36). Similar results were obtained by Galon et al (30), Ishizuka et al (38) and Prall et al (43). In the present study, a statistically significant association between stromal TILs and DFS was not observed. However, a shorter DFS time for patients without intraepithelial TILs in the center of the primary tumor of colon cancer was identified. Similar observations have been made for cancers of the ovary and uterus $(43,44)$. Stumpf et al (44) observed patients with serous stage III ovarian carcinomas, in which the presence of high numbers of intraepithelial CD3-positive T lymphocytes was associated with an improved DFS. A high level of intraepithelial CD8 ${ }^{+}$ $\mathrm{PD}^{+}$TIL infiltrate in endometrial adenocarcinoma was associated with an improved prognosis (45). Multi- and univariate analyses did not confirm the prognostic and predictive values of stromal and intraepithelial TILs in patients with CRC in the population of the present study; however, the identified correlations with clinical parameters and DFS demonstrate that TILs at the invasive front and in the center of the tumor require additional detailed immunophenotyping analysis on a larger group, and may present a potentially notable parameter in the assessment of the morphological features of CRC tumors in the future.

The results of the present study confirmed that the infiltration of TILs in the invasive front and center of the tumor in patients with CRC serves an important role in the invasion and progression of CRC, and thus, that the evaluation of TIL infiltration should be included in routine histopathological examinations. 


\section{References}

1. Toh JW, de Souza P, Lim SH, Singh P, Chua W, Ng W and Spring KJ: The potential value of immunotherapy in colorectal cancers: Review of the evidence for programmed death-1 inhibitor therapy. Clin Colorectal Cancer 15: 285-291, 2016.

2. Dong ZY, Wu SP, Liao RQ, Huang SM and Wu YL: Potential biomarker for checkpoint blockade immunotherapy and treatment strategy. Tumour Biol 37: 4251-4461, 2016.

3. Jakóbisiak M and Lasek W: Immunologia nowotworów. In: Gołąb J, Jakóbisiak M, Lasek W, Stokłosa T (eds). 5th Edition. Immunologia. Wydawnictwo Naukowe PWN, Warszawa, pp478-484, 2007 (In Polish).

4. Taube JM, Klein A, Brahmer JR, Xu H, Pan X, Kim JH, Chen L, Pardoll DM, Topalian SL and Anders RA: Association of PD-1, PD-1 ligands, and other features of the tumor immune microenvironment with response to anti-PD-1 therapy. Clin Cancer Res 20: 5064-5074, 2014.

5. Weedon D, LeBoit G, Burg G and Sarasin A: Pathology and Genetics of Tumours of the Skin. IARC Press, ISBN 9283224140 , 2005 .

6. Thomas NE, Busam KJ, From L, Kricker A, Armstrong BK, Anton-Culver H, Gruber SB, Gallagher RP, Zanetti R, Rosso S, et al: Tumor-infiltrating lymphocyte grade in primary melanomas is independently associated with melanoma-specific survival in the population-based genes, environment and melanoma study. J Clin Oncol 31: 4252-4259, 2013.

7. Taylor RC, Patel A, Panageas KS, Busam KJ and Brady MS: Tumor-infiltrating lymphocytes predict sentinel lymph node positivity in patients with cutaneous melanoma. J Clin Oncol 25: 869-875, 2007.

8. Pardoll DM: The blockade of immune checkpoints in cancer immunotherapy. Nat Rev Cancer 12: 252-264, 2012.

9. Fanoni D, Tavecchio S, Recalcati S, Balice Y, Venegoni L, Fiorani R, Crosti C and Berti E: New monoclonal antibodies against B-cell antigens: Possible new strategies for diagnosis of primary cutaneous B-cell lymphomas. Immunol Lett 134: 157-160, 2011

10. Thompson RH, Gillett MD, Cheville JC, Lohse CM, Dong H, Webster WS, Krejci KG, Lobo JR, Sengupta S, Chen L, et al: Costimulatory B7-H1 in renal cell carcinoma patients: Indicator of tumor aggressiveness and potential therapeutic target. Proc Natl Acad Sci USA 101: 17174-17179, 2004.

11. Salgado R, Denkert C, Demaria S, Sirtaine N, Klauschen F, Pruneri G, Wienert S, Van den Eynden G, Baehner FL, Penault-Llorca F, et al: The evaluation of tumor-infiltrating lymphocytes (TILs) in breast cancer: Recommendations by an International TILs Working Group 2014. Ann Oncol 26: 259-271, 2015.

12. Ingold Heppner B, Untch M, Denkert C, Pfitzner BM, Lederer B, Schmitt W, Eidtmann H, Fasching PA, Tesch H, Solbach C, et al: Tumor-infiltrating lymphocytes: A predictive and prognostic biomarker in neoadjuvant-treated HER2-positive breast cancer. Clin Cancer Res 22: 5747-5754, 2016.

13. Loi S, Sirtaine N, Piette F, Salgado R, Viale G, Van Eenoo F, Rouas G, Francis P, Crown JP, Hitre E, et al: Prognostic and predictive value of tumor-infiltrating lymphocytes in a phase III randomized adjuvant breast cancer trial in node-positive breast cancer comparing the addition of docetaxel to doxorubicin with doxorubicin-based chemotherapy: BIG 02-98. J Clin Oncol 31: $860-867,2013$.

14. Adams S, Gray RJ, Demaria S, Goldstein L, Perez EA, Shulman LN, Martino S, Wang M, Jones VE, Saphner TJ, et al: Prognostic value of tumor-infiltrating lymphocytes (TILs) in triple negative breast cancers (TNBC) from two phase III randomized adjuvant breast cancer trials: ECOG 2197 and ECOG 1199. J Clin Oncol 32: 2959-2966, 2014.

15. Loi S, Michiels S, Salgado R, Sirtaine N, Jose V, Fumagalli D, Kellokumpu-Lehtinen PL, Bono P, Kataja V, Desmedt C, et al: Tumor infiltrating lymphocytes are prognostic in triple negative breast cancer and predictive for trastuzumab benefit in early breast cancer: Results from the FinHER trial. Ann Oncol 25: 1544-1550, 2014

16. Oken MM, Creech RH, Tormey DC, Horton J, Davis TE, McFadden ET and Carbone PP: Toxicity and response criteria of the eastern cooperative oncology group. Am J Clin Oncol 5: 649-655, 1982

17. NCCN Clinical Practice Guidelines in Oncology: Colon Cancer www.nccn.org.asp. Accessed January 20, 2017.
18. Turnbull RB Jr, Kyle K, Watson FR and Spratt J: Cancer of the colon: The influence of the no touch isolation technique on survival rates. Ann Surg 166: 420-427, 1967.

19. Therasse P, Arbuck SG, Eisenhauer EA, Wanders J, Kaplan RS, Rubinstein L, Verweij J, Van Glabbeke M, van Oosterom AT, Christian MC and Gwyther SG: New guidelines to evaluate the response to treatment in solid tumors. European Organization for Research and Treatment of Cancer, National Cancer Institute of the United States, National Cancer Institute of Canada. J Nat Cancer Inst 92: 205-216, 2000.

20. Lin Q, Wei Y, Ren L, Zhong Y, Qin C, Zheng P, Xu P, Zhu D, $\mathrm{Ji} \mathrm{M}$ and $\mathrm{Xu} \mathrm{J}$ : Tumor deposit is a poor prognostic indicator in patients who underwent simultaneous resection for synchronous colorectal liver metastases. Onco Targets Ther 8: 233-240, 2015.

21. Huijbers A, Tollenaar RA, v Pelt GW, Zeestraten EC, Dutton S, McConkey CC, Domingo E, Smit VT, Midgley R, Warren BF, et al: The proportion of tumor-stroma as a strong prognosticator for stage II and III colon cancer patients: Validation in the VICTOR trial. Ann Oncol 24: 179-185, 2013.

22. Morodomi T, Isomoto H, Shirouzu K, Kakegawa K, Irie K and Morimatsu M: An index for estimating the probability of lymph node metastasis in rectal cancers. Lymph node metastasis and the histopathology of actively invasive regions of cancer. Cancer 63: $539-543,1989$

23. Klintrup K, Mäkinen JM, Kauppila S, Väre PO, Melkko J, Tuominen H, Tuppurainen K, Mäkelä J, Karttunen TJ and Mäkinen MJ: Inflammation and prognosis in colorectal cancer. Eur J Cancer 41: 2645-2654, 2005.

24. Richards CH, Flegg KM, Roxburgh CS, Going JJ, Mohammed Z, Horgan PG and McMillan DC: The relationships between cellular components of the peritumoural inflammatory response, clinicopathological characteristics and survival in patients with primary operable colorectal cancer. Br J Cancer 106: 2010-2015, 2012.

25. Väyrynen JP, Sajanti SA, Klintrup K, Mäkelä J, Herzig KH, Karttunen TJ, Tuomisto A and Mäkinen MJ: Characteristics and significance of colorectal cancer associated lymphoid reaction. Int J Cancer 134: 2126-2135, 2014.

26. Ueno H, Jones AM, Wilkinson KH, Jass JR and Talbot IC: Histological categorization of fibrotic cancer stroma in advanced rectal cancer. Gut 53: 581-586, 2004.

27. Frisch M, Biggar RJ, Engels EA and Goedert JJ; AIDS-Cancer Match Registry Study Group: Association of cancer with AIDS-related immunosuppression in adults. JAMA 285: $1736-1745,2001$

28. Pernot S, Terme M, Voron T, Colussi O, Marcheteau E, Tartour E and Taieb J: Colorectal cancer and immunity: What we know and perspectives. World J Gastroenterol 20: 3738-3750, 2014.

29. Shankaran V, Ikeda H, Bruce AT, White JM, Swanson PE, Old LJ and Schreiber RD: IFNgamma and lymphocytes prevent primary tumour development and shape tumour immunogenicity. Nature 410: 1107-1111, 2001.

30. Galon J, Costes A, Sanchez-Cabo F, Kirilovsky A, Mlecnik B, Lagorce-Pagès C, Tosolini M, Camus M, Berger A, Wind P, et al: Type, density, and location of immune cells within human colorectal tumors predict clinical outcome. Science 313: 1960-1964, 2006.

31. Jass JR, Ajioka Y, Allen JP, Chan YF, Cohen RJ, Nixon JM, Radojkovic M, Restall AP, Stables SR and Zwi LJ: Assessment of invasive growth pattern and lymphocytic infiltration in colorectal cancer. Histopathology 28: 543-548, 1996

32. Ogino S, Nosho K, Irahara N, Meyerhardt JA, Baba Y, Shima K, Glickman JN, Ferrone CR, Mino-Kenudson M, Tanaka N, et al: Lymphocytic reaction to colorectal cancer is associated with longer survival, independent of lymph node count, microsatellite instability, and $\mathrm{CpG}$ island methylator phenotype. Clin Cancer Res 15: 6412-6420, 2009.

33. Seitz S, Schneider CK, Malotka J, Nong X, Engel AG, Wekerle H, Hohlfeld R and Dornmair K: Reconstitution of paired T cell receptor alpha- and beta-chains from microdissected single cells of human inflammatory tissues. Proc Natl Acad Sci USA 103: 12057-12062, 2006.

34. Huh JW, Lee JH and Kim HR: Prognostic significance of tumor-infiltrating lymphocytes for patients with colorectal cancer. Arch Surg 147: 366-372, 2012

35. Pagès F, Galon J and Fridman WH: The essential role of the in situ immune reaction in human colorectal cancer. J Leukoc Biol 84: 981-987, 2008.

36. Pagès F, Berger A, Camus M, Sanchez-Cabo F, Costes A, Molidor R, Mlecnik B, Kirilovsky A, Nilsson M, Damotte D, et al: Effector memory $\mathrm{T}$ cells, early metastasis, and survival in colorectal cancer. N Engl J Med 353: 2654-2666, 2005. 
37. Perez RO, Habr-Gama A, dos Santos RM, Proscurshim I, Campos FG, Rawet V, Kiss D and Cecconello I: Peritumoral inflammatory infiltrate is not a prognostic factor in distal rectal cancer following neoadjuvant chemoradiation therapy. J Gastrointest Surg 11: 1534-1540, 2007.

38. Ishizuka M, Nagata $\mathrm{H}$, Takagi $\mathrm{K}$ and Kubota $\mathrm{K}$ : Influence of inflammation-based prognostic score on mortality of patients undergoing chemotherapy for far advanced or recurrent unresectable colorectal cancer. Ann Surg 250: 268-272, 2009.

39. Wagner P, Koch M, Nummer D, Palm S, Galindo L, Autenrieth D, Rahbari N, Schmitz-Winnenthal FH, Schirrmacher V, Büchler MW, et al: Detection and functional analysis of tumor infiltrating T-lymphocytes (TIL) in liver metastases from colorectal cancer. Ann Surg Oncol 15: 2310-2317, 2008.

40. Schweiger T, Berghoff AS, Glogner C, Glueck O, Rajky O, Traxler D, Birner P, Preusser M, Klepetko W and Hoetzenecker K: Tumor-infiltrating lymphocyte subsets and tertiary lymphoid structures in pulmonary metastases from colorectal cancer. Clin Exp Metastasis 33: 727-739, 2016.

41. Fu Z, Zuo Y, Li D, Xu W, Li D, Chen H and Zheng S: The crosstalk: Tumor-infiltrating lymphocytes rich in regulatory $\mathrm{T}$ cells suppressed cancer-associated fibroblasts. Acta Oncol 52: 1760-1770, 2013.
42. Barsky SH and Gopalakrishna R: Increased invasion and spontaneous metastasis of BL6 melanoma with inhibition of the desmoplastic response in C57 BL/6 mice. Cancer Res 47: 1663-1667, 1987.

43. Prall F, Dührkop T, Weirich V, Ostwald C, Lenz P, Nizze H and Barten M: Prognostic role of $\mathrm{CD}^{+}$tumor-infiltrating lymphocytes in stage III colorectal cancer with and without microsatellite instability. Hum Pathol 35: 808-816, 2004.

44. Stumpf M, Hasenburg A, Riener MO, Jütting U, Wang C, Shen Y, Orlowska-Volk M, Fisch P, Wang Z, Gitsch G, et al: Intraepithelial CD8-positive T lymphocytes predict survival for patients with serous stage III ovarian carcinomas: Relevance of clonal selection of T lymphocytes. Br J Cancer 101: 1513-1521, 2009.

45. Workel HH, Komdeur FL, Wouters MC, Plat A, Klip HG, Eggink FA, Wisman GB, Arts HJ, Oonk MH, Mourits MJ, et al: CD103 defines intraepithelial $\mathrm{CD}^{+} \mathrm{PD}^{+}$tumour-infiltrating lymphocytes of prognostic significance in endometrial adenocarcinoma. Eur J Cancer 60: 1-111, 2016. 